\title{
Methylenetetrahydrofolate Reductase (677C/T) Polymorphism in Myocardial Infarction and Hypertension
}

\author{
${ }^{1}$ Hatem Al-Kordy Amin, ${ }^{2}$ Hanaa Fahmy Abdel Aziz, \\ ${ }^{2}$ Ola Farouk Leheta and ${ }^{3}$ Hanan Kamal \\ ${ }^{1}$ Department Biochemistry and Molecular Biology, Faculty of Pharmacy, Helawan University, Egypt \\ ${ }^{2}$ Department Clinical Pathology, Faculty of Medicine, Hospital Suez Canal University, Egypt \\ ${ }^{3}$ Department Cardiology, Faculty of Medicine, Hospital Suez Canal University, Egypt
}

Received 2012-04-08, Revised 2012-07-02; Accepted 2012-07-20

\begin{abstract}
Hyperhomocysteinemia is a well-established risk factor for cardiovascular disease and hypertension. This study aimed to assess the MTHFR gene polymorphisms $(677 \mathrm{C} / \mathrm{T})$ as a potential genetic risk factor for hypertension and Myocardial Infarction (MI) in Egypt. Myocardial infarction and hypertensive diagnosed patients were divided into two groups; first comprised 50 patients aged $<45$ years, second comprised 47 patient aged $>45$ years and a third control group comprised 84 . CT genotype was significantly higher in the first group (48.8\%) versus control group (30\%) and second group $(29.4 \%)$ with (OR $2.35,95 \%$ CI $1.3-4.2, p=0.006)$. The percentage of TT genotype was $4.7,11.8$ and $15 \%$ in the three groups respectively. The percentage of MTHFR $677 \mathrm{C} \rightarrow \mathrm{T}$ polymorphism was significantly higher in patients with hypertension than normotensive. MTHFR $677 \mathrm{C} \rightarrow$ T polymorphism in Egyptian MI and hypertensive patients has no direct role in developing such diseases but in combination with high levels of cholesterol, LDL-C and triglycerides might constitute a probable potentiating factor for MI and hypertension among Egyptian patients and could not be used as a predictor for early diagnosis without considering other factors.
\end{abstract}

Keywords: MTHFR 677C $\rightarrow$ T Gene Polymorphism, Hyperhomocysteinemia, Hypertension, Myocardial Infarction, Egyptian Patients

\section{INTRODUCTION}

Myocardial Infarction (MI) and Hypertension are well-known prevalent disorders among Egyptians. Inadequate data were published concerning Coronary Artery Disease (CAD) susceptibility in Egyptian patients in terms of their genetic background.

The aim of this work is to study the presence of MTHFR gene polymorphisms as a genetic risk factor for

Morbidity and mortality due to Essential Hypertension (ET) and CAD are significant more frequent in developing countries with associated several risk factors such as advancing age, male gender, hyperlipidemia, diabetes and insulin resistance (Laraqui et al., 2007). Acute Myocardial Infarction (MI) among young adults is about 5 and $10 \%$ of hypertension and MI among Egyptian patients.

all MIs (Choudhury and Marsh, 1999; Doughty et al., 2002). Young patients with managed MI are characterized by family history of CAD, heavy smoking and apparently normal angiographically (Zimmerman et al., 1995; Panagiotakos et al., 2007). MI in young patients is resulted from multiple pathogenetic mechanisms; coronary spasm, coronary embolism and thrombus formation resulted from non-obstructive plaque rupture and endothelial layer erosion separately or in combination (Kardasz and Caterina, 2007; Verheugt et al., 1987; Romagnoli and Lanza, 2007).

MTHFR gene common polymorphism remains controversial in its atherosclerotic potential, although Hyperhomocysteinemia is being established as CAD risk factor (Choudhury and Marsh, 1999; Zimmerman et al., 1995; Panagiotakos et al., 2007; Kardasz and Caterina, 2007; Zee et al., 2007; Ogawa et al., 2003; Doughty et al., Corresponding Author: Hatem Al-Kordy Amin, Department Biochemistry and Molecular Biology, Faculty of Pharmacy, Helawan University, Egypt 
2002). About 10 mutations in the MTHFR locus were identified and the most common missense mutation, a $677 \mathrm{C} \rightarrow \mathrm{T}$ substitution (alanine to valine) resulting in reduced remethylation of homocysteine leading to a thermo labile enzyme variant which develops Hyperhomocysteinemia (Sadeghian et al., 2006; Nikfardjam et al., 2001; Payne et al., 2001).

Many reported conflicting data regarding the association between the MTHFR $677 \mathrm{C} \rightarrow \mathrm{T}$ polymorphism and the risk of CAD (Zee et al., 2007; Schmitz et al., 1996; Jee et al., 2000). A case-control meta-analysis showed a higher risk of CAD of individuals with the MTHFR 677TT genotype, while another meta-analysis is carried out later did not support this relation in North America, Australia and Europe, (Klerk et al., 2002; Lewis et al., 2005). Hyperhomocysteinemia due to MTHFR gene $\mathrm{T}$ allele homozygosity in hypertensive patients could be an independent risk factor for early atherosclerotic organ damage development (Ravera et al., 2001).

\section{MATERIALS AND METHODS}

Patients were recruited from consecutive admission to the coronary care unit, Suez Canal University Hospital, Ismailia, Egypt. All prerequisites demanded by the Faculty research ethical committee were considered and fulfilled for our patients.

A-Priori test was performed to identify the requested numbers of subjects in each group using anticipated effect size (Cohen's d) (0.5), Desired statistical power level (0.8) and Probability level (0.02). The obtained calculations were Minimum total sample size (one-tailed hypothesis) (138), Minimum sample size per group (onetailed hypothesis) (69); Minimum total sample size (twotailed hypothesis) (164), Minimum sample size per group (two-tailed hypothesis) (82).

The recruited subjects (total 181) were subdivided into two main groups; patients (total 97) and control group (total 84). The patients group was subdivided into two main subgroups, the first group comprised (50) young adults aged $<45$ years and the second one comprised (47) older adults aged $\geq 45$ years.

On admission, the following data were fulfilled for all recruited groups: age, smoking, history of Diabetes Mellitus (DM) and Hypertension (HTN), family history of MI and stroke. Clinical examination: Blood pressure examination and Body Mass Index (BMI) calculation were carried out and for patient groups (1 and 2) a short outcome prognosis was done using left ventricular Ejection Fraction (EF). Routine laboratory investigations for all recruited groups including fasting and postprandial glucose level, Triglycerides, total Cholesterol, HDL-C and LDL-C were carried out using Hitachi 912 auto-analyzer (Roche Diagnostics GmbH. Str. Mannheim, Germany).

\subsection{MTHFR (677C/T) Polymorphism Genotyping}

Diagnosis of patients with acute MI was based on full history taking, clinical examination, resting ECG, cardiac enzymes and echocardiography. MI was defined either by presence of ST-Segment Elevation (STE) or depression (non-STE) at the J-point $\geq 1 \mathrm{~mm}$ in two or more contiguous leads, In leads V2 and V3, $2 \mathrm{~mm}$ of ST elevation in men and $1.5 \mathrm{~mm}$ in women was required, new left bundle branch block or development of pathologic $Q$ and a rise and/or fall in cardiac troponin with at least one value above the 99th percentile of the upper reference limit (troponin I levels $>$ $0.1 \mathrm{ng} / \mathrm{mL}$ ) and elevated CK-MB is enzyme (Tàssies et al., 2009; Thygesen et al., 2007).

Hyperlipidemia was defined as total Cholesterol $>220$ $\mathrm{mg} / \mathrm{dL}$, Triglycerides $>150 \mathrm{mg} / \mathrm{dL}$ or treatment with lipid lowering drugs. Diabetes was defined as patients with random glycemia $>200 \mathrm{mg} / \mathrm{dL}$ at admission or $\mathrm{FBG}>125$ $\mathrm{mg} / \mathrm{dL}$ in two determinations or receiving insulin or oral hypoglycemic drugs; hypertension was defined as repeated blood pressure $\geq 140 / 90 \mathrm{mmHg}$ or previous treatment with antihypertensive drugs (Chobanian et al., 2003).

Genomic DNA was extracted from peripheral blood leucocytes using silica membrane based DNA purification method (Qiamp DNA blood kit, Qiagen, Germany). Real time PCR Rotor-GeneTM 6000 (Corbett Research, Mortlake, NSW, 2137, Australia) was used for MTHFR $(677 \mathrm{C} \rightarrow \mathrm{T})$ genotyping.

Primers 5'-AAAGCGGAAGAATGTGTCAGC-3' and (5'-GACATCTGTGTGGCAGGTTACC-3`) were used yielding 97bp amplicon.

Two TaqMan probes were designed and used (5 TGATGATGAAATCGACTCCCGCAGA-FAM-3`) for T-allele and (5-TGATGATGAAATCGGCTCCCGCTET-3') for C-allele. PCR reaction mixture consisted of $0.1 \mu \mathrm{g}$ of DNA; QPCR master mix provided from Qiagen, Germany was used. $400 \mathrm{nM}$ from each primer and $150 \mathrm{nM}$ from each probe were added in final $25 \mu \mathrm{l}$ reaction volume. PCR cycles were optimized as follow: $95^{\circ} \mathrm{C}$ for $15 \mathrm{~min}$. for initial enzyme activation and DNA denaturing; 40 cycles $\left(95^{\circ} \mathrm{C}\right.$ for $15 \mathrm{sec}$., $58^{\circ} \mathrm{C}$ for 60 $\mathrm{sec}$ ); final cycle $72^{\circ} \mathrm{C}$ for $10 \mathrm{~min}$.

\subsection{Statistical Analysis}

Baseline characteristics of the study population were presented as frequencies and percentages (\%) or mean values and Standard Deviations (SD). Age, smoking, history of DM, HTN, stroke were treated as categorized variables. Age, cholesterol, triglycerides, HDL, LDL, FBG, PPBG, BMI, EF, systolic and diastolic blood pressure were treated as continuous variables. Differences between frequencies in both groups were compared by Chi-square test when all expected values in $2 \times 2$ table $>5$ or Fisher exact test when one of the expected values in $2 \times 2$ table $<5$. Differences between means in both groups were compared by Student's t-test. 
Table 1a. Data characteristics among patients and control groups

\begin{tabular}{llll}
\hline Characteristic & Control $(\mathrm{n}=84)$ & Patients $(\mathrm{n}=97)$ & $\mathrm{p}$-value \\
\hline Smokers $(\%)$ & $32(38.1 \%)$ & $64(66 \%)$ & $<0.0001^{* *}$ \\
Cholesterol (mg/dL) & $177.96 \pm 26.34$ & $240.12 \pm 72.7$ & $<0.0001^{* *}$ \\
Triglycerides (mg/dL) & $93.77 \pm 26.94$ & $159.73 \pm 51.57$ & $<0.0001^{* *}$ \\
HDL-C (mg/dL) & $56.92 \pm 14.16$ & $35.37 \pm 5.42$ & $<0.0001^{* *}$ \\
LDL-C (mg/dL) & $124.73 \pm 24.94$ & $169.24 \pm 72.7$ & $<0.0001^{* *}$ \\
Systolic BP (mmHg) & $114.63 \pm 9.34$ & $141.32 \pm 12.87$ & $<0.0001^{* *}$ \\
Diastolic BP (mmHg) & $77.92 \pm 9.79$ & $89.11 \pm 8.47$ & $<0.0001^{* *}$ \\
RBS & $91.4 \pm 12.7$ & $279.7 \pm 104.2$ & $<0.0001^{* *}$ \\
\hline
\end{tabular}

**Significant $\mathrm{p}$-value (2-tailed) $\leq 0.05$

Table 1b. Data characteristics among younger and older patients

\begin{tabular}{llll}
\hline Characteristic & Younger age $(\mathrm{n}=50)$ & Older age $(\mathrm{n}=47)$ & P value \\
\hline Smokers (\%) & $33(66 \%)$ & $31(66 \%)$ & 1.0000 \\
DM (\%) & $26(52 \%)$ & $31(66 \%)$ & 0.1600 \\
HTN (\%) & $29(58 \%)$ & $27(57.4 \%)$ & 1.0000 \\
MI (\%) & $30(60 \%)$ & $32(68.1 \%)$ & 0.4100 \\
Stroke (\%) & $0(0 \%)$ & $0(0 \%)$ & 1.0000 \\
BMI & $27.75 \pm 1.89$ & $28.08 \pm 1.77$ & 0.3800 \\
Cholesterol (mg/dL) & $266 \pm 85.58$ & $212.6 \pm 41.54$ & $0.0002^{* *}$ \\
Triglycerides (mg/dL) & $178.10 \pm 49.96$ & $140.19 \pm 46.21$ & $0.0002^{* *}$ \\
HDL-C (mg/dL) & $35.70 \pm 5.1$ & $35.02 \pm 5.78$ & 0.5400 \\
LDL-C (mg/dL) & $192.02 \pm 86.72$ & $145 \pm 43.08$ & $0.0012^{* *}$ \\
Systolic BP (mmHg) & $138.85 \pm 9.8$ & $143.83 \pm 15.08$ & 0.0550 \\
Diastolic BP (mmHg) & $87.81 \pm 8.44$ & $90.43 \pm 8.39$ & 0.1300 \\
FBS (mgdL) & $143.34 \pm 46.67$ & $161.02 \pm 55.99$ & 0.0940 \\
PPBS (mg/dL) & $220.80 \pm 83.21$ & $250.23 \pm 98.18$ & 0.1100 \\
Ejection fraction & $42.56 \pm 6.52$ & $44.94 \pm 7.61$ & 0.1000 \\
\hline
\end{tabular}

**Significant p-value (2-tailed) $\leq 0.05$

Differences between multiple groups were compared by Analysis Of Variance (ANOVA) test. A p value of $<0.05$ was considered significant. The Relative Risk (RR) for MI (estimated as Odds Ratios (OR) and 95\% Confidence Intervals (CI)) for those homozygous for the TT allele was compared with the risk for those who carried the CC allele. With a total of 43 younger and 34 older cases, it is estimated that for a statistical power of $80 \%$, OR $\geq 2$ will be significant at the 5\% level. Pearson correlation coefficient test was used after controlling of age variable to correlate the dependent variable (MTHFR 677C $\rightarrow$ T genotypes) and other independent variable (predictors). Logistic regression was performed to estimate the effect of the MTHFR $677 \mathrm{C} / \mathrm{T}$ polymorphism. Logistic regression with adjustment for age and sex was performed on each variable to estimate OR and p-value. The Chi-square test was used to evaluate deviations of genotype distribution and Hardy-Weinberg equilibrium was tested for all groups.

\section{RESULTS}

The systolic and diastolic blood pressure, smoking, FBG, PPBG, Cholesterol, Triglycerides, HDL-C and LDL$\mathrm{C}$ showed significant difference between patients groups and control group (Table 1a). Cholesterol, Triglycerides and LDL-C showed significant difference between young patients group and old patients group (Table 1b).
Genotyping of the control group and patients group showed wild CC allele 56 versus $58.8 \%$, CT allele 35.7 versus $34 \%$ and TT allele 8.3 versus $7.2 \%$ respectively. While Genotyping of patients two subgroups showed younger patients group was significantly different than older patients group for both CT and TT alleles (OR 2.06, 95\% CI 1.13$3.75, p=0.02$ and OR 7.17, 95\% CI 0.83-61.01, $p=0.047$ respectively) showing higher tendency for $\mathrm{CT}$ genotype in young group and TT genotype in older group, patients in young group with CT genotype 42 versus $25.5 \%$ in the older group and $35.7 \%$ while, patients in young group with TT genotype was 2 versus $6 \%$ in the older group and $8.3 \%$ in controls (Table 2a-c and 3a, b). Correlations between genotypes and other variables after controlling of age showed no significant correlation between MTHFR $677 \mathrm{C} \rightarrow \mathrm{T}$ polymorphism and DM, HTN, Cholesterol, TG, HDL-C, LDL-C, FBG, PPBG, SBP, DBP and smoking. Logistic regression analysis test with MTHFR $677 \mathrm{C} \rightarrow \mathrm{T}$ polymorphism as dependent variable showed that DM, HTN, Cholesterol, TG, HDL-C, LDL-C, FBG, PPBG, SBP, DBP and smoking were found to be insignificant independent risk factor for the development of MI. Percentage of MTHFR $677 \mathrm{C} \rightarrow \mathrm{T}$ polymorphism showed significant increase in patient with cholesterol and hypertension than in normotensive patients. However no significant difference was found in this polymorphism associated with other risk factors (Table 4). HardyWeinberg equilibrium showed consistent equilibrium at $\mathrm{p}>0.05 \quad$ (Table 
Table 2a. Genotype of MTHFR gene polymorphism among younger, older patients groups

\begin{tabular}{llll}
\hline Genotype & Younger age $(\mathrm{n}=50)$ & Older age $(\mathrm{n}=47)$ & $\mathrm{p}$-value \\
\hline Wild (CC) & $28(56 \%)$ & $29(61.7 \%)$ & 0.57 \\
Hetero (CT) & $21(42 \%)$ & $12(25.5 \%)$ & $0.02^{*}$ \\
Homo (TT) & $1(2 \%)$ & $6(12.8 \%)$ & $0.047^{*}$ \\
\hline *Significant p-value (2-tailed) $<0.05$ & &
\end{tabular}

*Significant p-value (2-tailed) $\leq 0.05$

Table 2b. Genotype of MTHFR gene polymorphism among younger patients and control groups

\begin{tabular}{llll}
\hline Genotype & Younger age $(\mathrm{n}=50)$ & Control $(\mathrm{n}=\mathrm{s} 84)$ & $\mathrm{p}$-value \\
\hline Wild (CC) & $28(56 \%)$ & $47(56 \%)$ & 1.00 \\
Hetero (CT) & $21(42 \%)$ & $30(35.7 \%)$ & 0.48 \\
Homo (TT) & $1(2 \%)$ & $7(8.3 \%)$ & $0.05^{*}$ \\
\hline
\end{tabular}

* Significant p-value (2-tailed) $\leq 0.05$

Table 2c. Genotype of MTHFR gene polymorphism among older patients and control groups

\begin{tabular}{llll}
\hline Genotype & Older age $(\mathrm{n}=47)$ & Control(n=84) & p-value \\
\hline Wild (CC) & $29(61.7 \%)$ & $47(56 \%)$ & 0.52 \\
Hetero (CT) & $12(25.5 \%)$ & $30(35.7 \%)$ & 0.23 \\
Homo (TT) & $6(12.8 \%)$ & $7(8.3 \%)$ & 0.54 \\
\hline
\end{tabular}

$\underline{\text { Table 3a. Odds ratio of genotypes of MTHFR gene polymorphism among younger and older age patients groups }}$

\begin{tabular}{lllllll}
\hline & & \multicolumn{5}{c}{ CI } \\
Genotype & Younger age $(\mathrm{n}=50)$ & Older age $(\mathrm{n}=47)$ & OR & Lower & Upper & p-value \\
\hline Wild (CC) & $28(56 \%)$ & $29(61.7 \%)$ & 0.79 & 0.35 & 1.78 & 0.57 \\
Hetero (CT) & $21(42 \%)$ & $12(25.5 \%)$ & 2.06 & 1.13 & 3.75 & $0.02 *$ \\
Homo (TT) & $1(2 \%)$ & $6(12.8 \%)$ & 7.17 & 0.83 & 61.01 & $0.047 *$ \\
\hline
\end{tabular}

*Significant p-value (2-tailed) $\leq 0.05$

Table 3b. Odds ratio of genotypes of MTHFR gene polymorphism among patients and control groups

\begin{tabular}{lllllll}
\hline & & \multicolumn{5}{c}{ CI } \\
Genotype & Patients $(\mathrm{n}=97)$ & Control $(\mathrm{n}=84)$ & OR & Lower & Upper & p-value \\
\hline Wild (CC) & $57(58.8 \%)$ & $47(56 \%)$ & 1.12 & 0.62 & 2.03 & 0.70 \\
Hetero (CT) & $33(34 \%)$ & $30(35.7 \%)$ & 0.93 & 0.50 & 1.71 & 0.81 \\
Homo (TT) & $7(7.2 \%)$ & $7(8.3 \%)$ & 0.86 & 0.29 & 2.54 & 0.78 \\
\hline
\end{tabular}

Table 4. The percentage of MTHFR $677 \mathrm{C} \rightarrow \mathrm{T}$ polymorphism in DM, SBP, DBP, Total cholesterol and Triglycerides

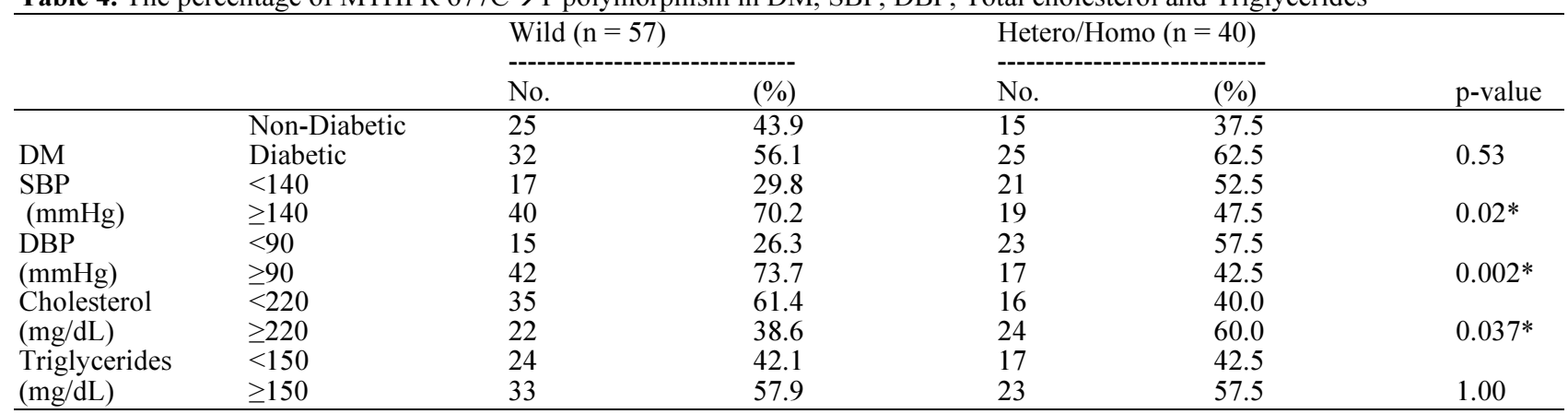

* Significant p-value (2-tailed) $\leq 0.05$

Table 5a.Hardy-Weinberg equilibrium for patients group

\begin{tabular}{lllll}
\hline & Patients & Expected & & \\
Genotypes & Observed \# & \# & $\mathrm{X}^{2}$ & P value \\
\hline Wild (CC) & 57 & 57 & & \\
Hetero (CT) & 33 & 35 & 0.39 & 0.82 \\
Homo (TT) & 7 & 5 & & \\
\hline
\end{tabular}

Consistent with Hardy-Weinberg equilibrium when $\mathrm{P}>0.05$
Table 5b. Hardy-Weinberg equilibrium

\begin{tabular}{|c|c|c|c|c|}
\hline Genotypes & $\begin{array}{l}\text { Control } \\
\text { observed \# }\end{array}$ & $\begin{array}{l}\text { Expected } \\
\#\end{array}$ & $X^{2}$ & $P$ value \\
\hline Wild (CC) & 47 & 47 & & \\
\hline Hetero $(\mathrm{CT})$ & 30 & 32 & 0.40 & 0.82 \\
\hline Homo (TT) & 7 & 5 & & \\
\hline
\end{tabular}

Consistent with Hardy-Weinberg equilibrium when $P>0.05$. 
Table 5c. Hardy-Weinberg Allele Frequencies in Patients populations

Allele frequencies in

patients populations

\begin{tabular}{llllll} 
& $\mathrm{A}(\mathrm{p})$ & $\mathrm{a}(\mathrm{q})$ & Total & $\mathrm{X}^{2}$ & P value \\
\hline Observed & 147 & 47 & 194 & & \\
Expected & 149 & 45 & 194 & 0.81 & 0.91
\end{tabular}

Consistent with Hardy-Weinberg equilibrium when $\mathrm{P}>0.05$.

Table 5d. Hardy-Weinberg Allele Frequencies in Patients populations

\begin{tabular}{|c|c|c|c|c|c|}
\hline & \multicolumn{3}{|c|}{$\begin{array}{l}\text { Allele Frequencies in } \\
\text { control populations }\end{array}$} & \multirow[b]{2}{*}{$X^{2}$} & \multirow[b]{2}{*}{$P$ value } \\
\hline & $A(p)$ & $a(q)$ & Total & & \\
\hline Observed & 124 & 44 & 168 & & \\
\hline Expected & 126 & 42 & 168 & 0.81 & 0.90 \\
\hline
\end{tabular}

Consistent with Hardy-Weinberg equilibrium

\section{DISCUSSION}

The present study aimed to assess the presence of Methylenetetrahydrofolatereductase $\quad 677 \mathrm{C} \rightarrow \mathrm{T}$ gene polymorphism and its relation to hypertension and Myocardial Infarction (MI) among Egyptian population. Genotyping of the control group and patients group showed wild CC allele 56 versus $58.8 \%$, CT allele 35.7 versus $34 \%$ and TT allele 8.3 versus $7.2 \%$ respectively. Genotype of CT and TT alleles between patients subgroups showed younger patients group was significantly different than older patients group for both CT and TT alleles (OR 2.06, 95\% CI 1.13-3.75, p $=0.02$ and OR 7.17, 95\% CI 0.83-61.01, p $=0.047$ respectively) showing higher tendency for CT genotype in young group and TT genotype in older group indicating that younger patients with CT allele are more affected with predictors for both $\mathrm{MI}$ and hypertension than older group. In Greece patients with premature MI the prevalence of TT homozygosity compared to controls was (27.1 Vs. 14.6\%) (Ravera et al., 2001). In a Southern Texan heterozygosity and homozygosity alleles were 39 and 7\%, respectively (Payne et al., 2001), while (Thygesen et al., 2007) meta analysis reported frequency of heterozygosity to be $34-59 \%$ and homozygosity to be $6-30 \%$ that came in match with current study results.

The current study showed significant higher prevalence of smoking, hypertension, DM, cholesterol, Triglycerides, HDL-C and LDL-C in MI and hypertensive patients than in controls which were in agreement with study carried out by another group in Greece (Ravera et al., 2001)

Patients with the TT genotype showed higher baseline Diastolic Blood Pressure (DBP) than those with the CC and CT genotypes ( $\mathrm{p}=0.018)$ ( $\mathrm{Xu}$ et al., 2012). Some studies found associations of TT homozygosity with premature CAD (Chobanian et al., 2003; Rallidis et al., 2008; Brattstrom et al., 1998) while others were negative (Gallagher et al., 1996; Mager et al., 1999; Gulec et al., 2001). Data from meta-analysis studies on cardiovascular disease risk assessment related to tHcy concentrations and MTHFR $677 \mathrm{C} \rightarrow \mathrm{T}$ genotypes are sometimes discordant. For example, a meta-analysis revealed that TT genotype was associated with a homocysteine concentration $25 \%$ higher than the CC genotype, but not with an increased risk of cardiovascular events (Thygesen et al., 2007). Another (Schwartz et al., 1997) meta-analysis reported an association between ischemic heart disease in European and $677 \mathrm{C} \rightarrow \mathrm{T}$ polymorphism but not detected in North American populations. Low dietary folate could aggravate the atherothrombotic potential effect of TT homozygosity by increasing the levels of homocysteine (Ravera et al., 2001). These discrepancies might be due to methodological aspects; First, the definition of premature CAD varied across these studies since the cutoff age ranged from 45 (Rallidis et al., 2008; Brattstrom et al., 1998; Gallagher et al., 1996) to 60 years (Mager et al., 1999); Second, the studied populations had different ethnic or geographic origin, i.e., Irish (Chobanian et al., 2003), Israeli Jews (Rallidis et al., 2008), Turkish (Brattstrom et al., 1998) suggesting that different nutritional habits might confound the results of genotype studies. While in Tunisia MTHFR gene C677T genotypes were not associated with MI in the Tunisian male population (Mourali et al., 2012) and matches with report from Mexico stating it is not possible to establish an association between the 677CT polymorphism of the MTHFR gene and the presence of heart disease in the Mexican mestizo population (Sanchez-Urbina et al., 2012).

The current study showed significant increase in the percentage of MTHFR $677 \mathrm{C} \rightarrow \mathrm{T}$ polymorphism (CT allele) in Egyptian young patients with $\mathrm{MI}$ and hypertension in comparison with old patients group but was insignificant compared to control group. This outcome might be explained by the inability of homocysteine remethylation yielding a thermo labile enzyme variant leading to Hyperhomocysteinemia which develops atherothrombosis (Panagiotakos et al., 2007; Kardasz and Caterina, 2007; Christensen et al., 1997). The European Concerted Action Project, a multicenter study of 750 patients with vascular disease and 800 control subjects, confirmed that Hyperhomocysteinemia is associated with an increased risk of vascular disease, however there was poor association between MTHFR $677 \mathrm{C} \rightarrow \mathrm{T}$ polymorphism and MI (Pinto et al., 2001; Klerk et al., 2002) which confirms this study results. 
The TT genotype of the $677 \mathrm{C} / \mathrm{T}$ MTHFR polymorphism is associated with Essential Hypertension (EH) and CAD. TT genotypes had higher plasma Hcy levels in CAD patients compared with $\mathrm{CC}$ and $\mathrm{CT}$ genotypes. The authors concluded that that MTHFR gene polymorphism is an independent risk factor for $\mathrm{EH}$ but not for CAD (Lentz, 2005).

This study showed that MTHFR $677 \mathrm{C} \rightarrow \mathrm{T}$ polymorphism among the Egyptian $\mathrm{MI}$ and hypertension patients was in accordance with the international percentage. Although no difference were detected among patients and controls but the existing CT genotype in combination with high levels of cholesterol, LDL-C and triglycerides might constitute a probable potentiating factor for MI and hypertension in younger patients while, the existing TT genotype in combination with high levels of cholesterol, LDL-C and triglycerides might constitute a probable potentiating factor in older patients.

\section{CONCLUSION}

MTHFR $677 \mathrm{C} \rightarrow \mathrm{T}$ polymorphism in Egyptian MI and hypertensive patients has no direct role in developing such diseases but in combination with high levels of cholesterol, LDL-C and triglycerides might constitute a probable potentiating factor for MI and hypertension among Egyptian patients and could not be used as a predictor for early diagnosis without considering the other factors.

\section{REFERENCES}

1. Brattstrom, L. D.E. Wilcken, J. Ohrvik and L. Brudin, 1998. Common methylenetetrahydrofolate reductase gene mutation leads to Hyperhomocysteinemia but not to vascular disease: The result of a meta-analysis. Circulation, 98: 25202526. PMID: 9843457

2. Chobanian, A.V., G.L. Bakris, H.R. Black, W.C. Cushman and L.A. Green et al., 2003. Seventh report of the joint national committee on prevention, detection, evaluation and treatment of high blood pressure. Hypertension, 42: 1206-52. PMID: 14656957

3. Choudhury, L. and J.D. Marsh, 1999. Myocardial infarction in young patients. Am. J. Med., 107: 254261. PMDI: 10492319

4. Christensen, B. P. Frosst, S. Lussier-Cacan, J. Selhub and P. Goyette et al., 1997. Correlation of a common mutation in the methylenetetrahydrofolate reductase gene with plasma homocysteine in patients with premature coronary artery disease. Arterioscler. Thromb. Vasc. Biol., 17: 569-573. PMID: 9102178
5. Doughty, M., R. Mehta, D. Bruckman, S. Das and D. Karavite et al., 2002. Acute myocardial infarction in the young--the university of michigan experience. Am. Heart J., 143: 56-62. PMDI: 11773912

6. Gallagher, P.M., R. Meleady, D.C. Shields, K.S. Tan and D. McMaster et al., 1996. Homocysteine and risk of premature coronary heart disease: Evidence for a common gene mutation. Circulation, 94: 2154-2158. PMID: 8901666

7. Gulec, S., O. Aras, E. Akar, E. Tutar and K. Omurlu et al., 2001. Methylenetetrahydrofolate reductase gene polymorphism and risk of premature myocardial infarction. Clin. Cardiol., 24: 281-284. PMID: 11303694

8. Jee, S.H., T.H. Beaty, I. Suh, Y. Yoon and L.J. Appel, 2000. The methylenetetrahydrofolate reductase gene is associated with increased cardiovascular risk in Japan, but not in other populations. Atherosclerosis, 153: 161168. PMID: 11058711

9. Kardasz, I. and R.D. Caterina, 2007. Myocardial infarction with normal coronary arteries: A conundrum with multiple aetiologies and variable prognosis: An update. J. Int. Med., 261: 330-348. PMID: 17391108

10. Klerk, M., P. Verhoef, R. Clarke, H.J. Blom and F.J. Kok et al., 2002. MTHFR studies collaboration group. MTHFR $677 \mathrm{C} \rightarrow \mathrm{T}$ polymorphism and risk of coronary heart disease: A meta-analysis. JAMA., 288: 2023-2031. DOI: 10.1001/jama.288.16.2023

11. Laraqui, A., A. Allami, A. Carrie, A. Raisonnier and A. Coiffard et al., 2007. Relation between plasma homocysteine, gene polymorphisms of homocysteine metabolism-related enzymes and angiographically proven coronary artery disease. Eur. J. Int. Med., 18: 474-483. PMID: 17822659

12. Lentz, S.R., 2005. Mechanisms of homocysteineinduced atherothrombosis. J. Thromb. Haemost, 3: 1646-1654. PMID: 16102030

13. Lewis, S.J., G.D. Smith and G. Davey, 2005. Metaanalysis of MTHFR $677 \mathrm{C} \rightarrow \mathrm{T}$ polymorphism and coronary heart disease: Does totality of evidence support causal role for homocysteine and preventive potential of folate? BMJ, 331: 1053-1053. DOI: $10.1136 / \mathrm{bmj} .38611 .658947 .55$

14. Mager, A., S. Lalezari, T. Shohat, Y. Birnbaum and Y. Adler et al., 1999. Methylenetetrahydrofolate reductase genotypes and early-onset coronary artery disease. Circulation 100: 2406-2410. DOI: 10.1161/ 01.CIR.100.24.2406

15. Mourali, M.S., A. Kallel, Y. Sdiri, S. Abdessalem and A. Zaroui et al., 2012. MTHFR gene C677T genotypes were not associated with MI in the Tunisian male population. Archives of Cardiovascular Diseases Supplements, 4: 20-20. 
16. Nikfardjam, M., S. Graf, S. Hornykewycz, G. Zorn and R. Huber-Beckmann et al., 2001. Homocysteine plasma levels in young patients with coronary artery disease: Relation to history of acute myocardial infarction and anatomical extent of disease. Thromb Res., 103: S359- S359. PMID: 11567667

17. Ogawa, M., S. Abe, M. Saigo, S. Biro and H. Toda et al., 2003. Homocysteine and hemostatic disorder as a risk factor for myocardial infarction at a young age. Thromb Res., 109: 253-258. PMID: 12818247

18. Panagiotakos, D.B., L.S. Rallidis, C. Pitsavos, C. Stefanadis and D. Kremastinos, 2007. Cigarette smoking and myocardial infarction in young men and women: A case-control study. Int. J. Cardiol., 116: 371-375. PMID: 16843552

19. Payne, D.A., A.J. Chamoun, S.L. Seifert and G.A. Stouffer, 2001. MTHFR 677C $\rightarrow$ T mutation: A predictor of early-onset coronary artery disease risk. Thromb. Res., 103: 275-279. PMID: 11562338

20. Pinto, X., M.A. Vilaseca, N. Garcia-Giralt, I. Ferrer and M. Pala et al., 2001. Homocysteine and the MTHFR 677C-->T allele in premature coronary artery disease. Case control and family studies. Eur. J. Clin. Invest., 31: 24-30. PMID: 11168435

21. Rallidis, L.S., A. Gialeraki, C. Komporozos, P. Vavoulis and G. Pavlakis et al., 2008. Role of methylenetetrahydrofolate reductase $677 \mathrm{C}->\mathrm{T}$ polymorphism in the development of premature myocardial infarction. Atherosclerosis, 200: 115-20. PMID: 18255072

22. Ravera, M., F. Viazzi, V. Berruti, G. Leoncini and P. Zagami et al., 2001. 5,10Methylenetetrahydrofolate reductase polymorphism and early organ damage in primary hypertension. Am. J. Hypertens, 14: 371-376. PMID: 11336184

23. Romagnoli, E. and G.A. Lanza, 2007. Acute myocardial infarction with normal coronary arteries: Role of coronary artery spasm and arrhythmic complications. Int. J. Cardiol., 117: 3-5. PMID: 17182140

24. Sadeghian, S., F. Fallahi, M. Salarifar, G. Davoodi and M. Mahmoodian et al., 2006. Homocysteine, vitamin b12 and folate levels in premature coronary artery disease. BMC Cardiovasc. Disord., 6: 38-38. DOI: $10.1186 / 1471-2261-6-38$

25. Sanchez-Urbina, R, C. Galaviz-Hernandez, J.A. Sierra-Ramirez, H. Rangel-Villalobos and R. Torres-Saldua et al., 2012. Methylenetetrahydrofolate reductase gene $677 \mathrm{CT}$ polymorphism and isolated congenital heart disease in a Mexican population. Rev. Esp. Cardiol., 65: 158-163. PMID: 22197386
26. Schmitz, C., K. Lindpaintner, P. Verhoef, J.M. Gaziano and J. Buring, 1996. Genetic polymorphism of methylenetetrahydrofolate reductase and myocardial infarction: A case-control study. Circulation, 94: 1812-1814. PMID: 8873653

27. Schwartz, S.M., D.S. Siscovick, M.R. Malinow, F.R. Rosendaal and R.K. Beverly et al., 1997. Myocardial infarction in young women in relation to plasma total homocysteine, folate and a common variant in the methylenetetrahydrofolate reductase gene. Circulation, 96: 412 417. PMID: 9244205

28. Tàssies, D., M. Roque, J. Monteagudo, T. Martorell and A. Sionis et al., 2009. Thrombin-activatable fibrinolysis inhibitor genetic polymorphisms as markers of the type of acute coronary syndrome. Thromb. Res., 124: 614-618. DOI: 10.1016/j.thromres.2009.07.004

29. Thygesen, K., J.S. Alpert and H.D. White, 2007. Universal definition of myocardial infarction. Eur. Heart J., 28: 2525-2538. PMID: 17951287

30. Verheugt, F.W., J.W.T. Cate, A. Sturk, L. Imandt and P.M. Verhorst et al., 1987. Tissue plasminogen activator activity and inhibition in acute myocardial infarction and angiographically normal coronary arteries. Am. J. Cardiol., 59: 1075-1079. PMID: 3107367

31. Xu, H., H. Zheng, Y. Shen, J. Huang and M. Luo et al., 2012. Polymorphism of the methylenetetrahydrofolate reductase gene C677T and its influence on the antihypertensive and vascular protective effects of short-term lercanidipine treatment, Gene, 500: 207-210. PMID: 22503897

32. Zee, R.Y., S. Mora, S. Cheng, H.A. Erlich and K. Lindpaintner et al., 2007. Homocysteine, 5,10methylenetetrahydrofolate reductase $677 \mathrm{C}>\mathrm{T}$ polymorphism, nutrient intake and incident cardiovascular disease in 24,968 initially healthy women. Clin. Chem., 53: 845-851. PMID: 17332146

33. Zimmerman, F.H., A. Camero, L.D. Fisher and G. $\mathrm{Ng}, 1995$. Myocardial infarction in young adults: Angiographic characterization, risk factors and prognosis (coronary artery surgery study registry). J. Am. Coll. Cardiol., 26: 654-661. PMID: 7642855 